\title{
Molecular Confirmation of $\mathrm{t}(6 ; 11)(\mathrm{p} 21 ; q 12)$ Renal Cell Carcinoma in Archival Paraffin-embedded Material Using a Break-apart TFEB FISH Assay Expands its Clinicopathologic Spectrum
}

\author{
Pedram Argani, MD ${ }^{\star}$, , Raluca Yonescu, MD*, Laura Morsberger, BA*, Kerry Morris, BA*, \\ George J. Netto, MD ${ }^{\star}$, , Nathan Smith, MD*, Nilda Gonzalez, MD*, Peter B. Illei, MD*, Marc \\ Ladanyi, MD $\ddagger$, and Constance A. Griffin, MD*, ${ }^{*}$, \\ *Department of Pathology, The Johns Hopkins Medical Institutions, Baltimore, MD \\ †Department of Oncology, The Johns Hopkins Medical Institutions, Baltimore, MD \\ ҒDepartment of Pathology, Memorial Sloan Kettering Cancer Center, New York, NY
}

\section{Abstract}

A subset of renal cell carcinomas (RCCs) is characterized by $\mathrm{t}(6 ; 11)(\mathrm{p} 21 ; \mathrm{q} 12)$, which results in fusion of the untranslated Alpha (MALAT1) gene to the TFEB gene. Only 21 genetically confirmed cases of $\mathrm{t}(6 ; 11) \mathrm{RCCs}$ have been reported. This neoplasm typically demonstrates a distinctive biphasic morphology, comprising larger epithelioid cells and smaller cells clustered around basement membrane material; however, the full spectrum of its morphologic appearances is not known. The $\mathrm{t}(6 ; 11) \mathrm{RCCs}$ differ from most conventional RCCs in that they consistently express melanocytic immunohistochemical (IHC) markers such as HMB45 and Melan A and the cysteine protease cathepsin K but are often negative for epithelial markers such as cytokeratins. TFEB IHC has been proven to be useful to confirm the diagnosis of $\mathrm{t}(6 ; 11) \mathrm{RCCs}$ in archival material, because native TFEB is upregulated through promoter substitution by the gene fusion. However, IHC is highly fixation dependent and has been proven to be particularly difficult for TFEB. A validated fluorescence in situ hybridization (FISH) assay for molecular confirmation of the $t(6 ; 11)$ RCC in archival formalin-fixed, paraffin-embedded material has not been previously reported. We report herein the development of a break-apart TFEB FISH assay for the diagnosis of $\mathrm{t}(6 ; 11)$ (p21;q12) RCCs. We validated the assay on 4 genetically confirmed cases and 76 relevant expected negative control cases and used the assay to report 8 new cases that expand the clinicopathologic spectrum of $\mathrm{t}(6 ; 11) \mathrm{RCC}$. An additional previously reported TFEB IHCpositive case was confirmed by TFEB FISH in 46-year-old archival material. In conclusion, TFEB FISH is a robust, clinically validated assay that can confirm the diagnosis of $\mathrm{t}(6 ; 11) \mathrm{RCC}$ in

\footnotetext{
Copyright $\odot 2012$ by Lippincott Williams \& Wilkins

Correspondence: Pedram Argani, MD, Department of Pathology, The Johns Hopkins Hospital, Weinberg Building, Room 2242, 401N Broadway, Baltimore, MD 21231-2410 (pargani@jhmi.edu).

Deceased.

Supplemental Digital Content is available for this article. Direct URL citations appear in the printed text and are provided in the HTML and PDF versions of this article on the journal's Website, www.ajsp.com.

Conflicts of Interest and Source of Funding: The authors have disclosed that they have no significant relationships with, or financial interest in, any commercial companies pertaining to this article.
} 
archival material and should allow a more comprehensive clinicopathologic delineation of this recently recognized neoplastic entity.

\section{Keywords}

TFEB; TFE3; FISH; translocation; renal cell carcinoma

The past decade has witnessed the characterization of a subset of renal cell carcinomas (RCCs) that have chromosomal translocations resulting in gene fusions involving members of the MiT subfamily of transcription factors. The best known members of this subset are the Xp11 translocation RCCs, which were recognized by the World Health Organization in 2004. ${ }^{1}$ These neoplasms comprise the majority of pediatric RCCs and a smaller percentage of adult RCCs and classically feature a papillary architecture lined by clear cells with extensive psammomatous calcification. ${ }^{2-8}$ Xp11 translocation RCCs are characterized by gene fusions involving the TFE3 transcription factor gene that maps to this locus; at least 5 different fusion partners for TFE3 have been identified to date..$^{2,3,5,9,10}$

A less well-known member of the translocation RCC family is the subset of RCCs characterized by $\mathrm{t}(6 ; 11)(\mathrm{p} 21 ; \mathrm{q} 12)$, which results in fusion of the untranslated Alpha (MALAT1) gene on 11q12 to the related TFEB gene on 6p21. ${ }^{11-14}$ Only 21 genetically confirmed cases of $\mathrm{t}(6 ; 11) \mathrm{RCCs}$ have been reported. ${ }^{5,11-23}$ This neoplasm typically demonstrates a distinctive biphasic morphology, comprising larger epithelioid cells and smaller cells clustered around basement membrane material; however, the full spectrum of its morphologic appearances is not known. The $\mathrm{t}(6 ; 11) \mathrm{RCC}$ differ from most conventional RCCs in that they consistently express melanocytic immunohistochemical (IHC) markers such as HMB45, Melan A, and the cysteine protease cathepsin $\mathrm{K}^{24,25}$ but are either negative or only focally positive for epithelial markers such as cytokeratins. ${ }^{11,12}$ On the basis of clinical, pathologic, and genetic similarities between the t(6;11) RCCs and the Xp11 translocation RCCs, we have proposed that these 2 neoplasms be classified together under the broader category of "MiT family translocation RCC." 12

Molecular confirmation of a diagnosis of a translocation RCC is relatively simple if fresh tissue is available for either cytogenetics or reverse transcriptase polymerase chain reaction assay using primers from the genes known to be involved in the gene fusion. However, in many cases, only archival, formalin-fixed, paraffin-embedded material is available. For the Xp11 translocation RCCs and $\mathrm{t}(6 ; 11) \mathrm{RCCs}$, IHC for TFE3 and TFEB, respectively, have proven to be useful for confirming the diagnosis in archival material. ${ }^{6,12}$ This is because both TFE3 fusion proteins and native TFEB are upregulated by promoter substitution by the gene fusions in these 2 RCCs relative to the level of expression of the respective native proteins. However, IHC is highly fixation dependent and has proven to be particularly difficult for TFE3 and TFEB for several reasons. These include the scarcity of genetically confirmed positive controls and the fact that the assays are optimally performed by overnight incubation, which is difficult to automate. ${ }^{26}$ Recently, break-apart fluorescence in situ hybridization (FISH) assays for TFE3 gene fusions were developed for archival material $^{27-29}$ and have allowed the expansion of the morphologic spectrum of the Xp11 
translocation RCCs. ${ }^{30}$ A validated FISH assay for molecular confirmation of $\mathrm{t}(6 ; 11) \mathrm{RCC}$ has not been reported previously.

We report herein the development of a break-apart TFEB FISH assay for the diagnosis of $\mathrm{t}(6 ; 11)(\mathrm{p} 21 ; \mathrm{q} 12) \mathrm{RCCs}$. We validated the assay on 4 genetically confirmed cases and 76 pertinent negative control cases, confirmed the presence of a TFEB gene rearrangement in a previously reported TFEB IHC-positive case from 46 years ago, and used the assay to report 8 new cases that expanded the clinicopathologic spectrum of $t(6 ; 11)$ RCCs.

\section{MATERIALS AND METHODS}

\section{Institutional Review Board Approval}

This study was approved by the institutional review board of The Johns Hopkins Medical Institution.

Cases

The known positive cases consisted of 4 cytogenetically confirmed $t(6 ; 11)(p 21 ; q 12)$ RCCs. Cases expected to be negative (expected negative control) included 22 clear cell (conventional) RCCs, 10 papillary RCCs, 16 Xp11 translocation RCCs, and 13 chromophobe RCCs. Aside from the Xp11 translocation RCCs, all of these expected negative control cases were typical examples of their respective entities, diagnosed on hematoxylin and eosin-stained sections. The Xp11 translocation RCCs were all confirmed to harbor TFE3 gene rearrangements by FISH. ${ }^{30}$ All of the expected negative control cases were negative for TFEB by IHC. We also studied 15 perivascular cell neoplasms (PEComas), including 3 arising in the soft tissue, 2 arising in the uterus, and 10 angiomyolipomas arising in the kidney (5 of which were predominantly epithelioid). In addition, we examined 8 previously unreported test cases that we suspected to be $\mathrm{t}(6 ; 11)$ (p21;q12) RCCs on the basis of a combination of young patient age, morphologic features (biphasic large cell/small cell population), and IHC profile (Melan A and cathepsin K immunoreactivity, in some cases TFEB immunoreactivity, and absence of TFE3 immunoreactivity) and 1 previously reported case verified only by TFEB IHC. ${ }^{16}$ IHC analysis was performed as previously described. ${ }^{4}$

\section{Fluorescence In Situ Hybridization}

FISH was performed with a probe consisting of 2 contigs that flank the TFEB gene on $6 \mathrm{p} 21$. The distal contig consists of 3 BAC/PAC clones (RP11-298J23, RP5-973N23, and RP11-533020) labeled with Spectrum Orange, and the proximal contig consists of 2 BAC/PAC clones (RP1-149M18 and RP11-328M4) labeled with Spectrum Green, from BacPac Resources at CHORI (Children's Hospital Oakland Research Institution), designed for research use. Sections of $5 \mu \mathrm{m}$ thickness were deparaffinized, dehydrated, and pretreated in a VP 2000 processor (Abbott Molecular), followed by subsequent treatment with pepsin. The probe mixture was applied, and the slides were incubated in a humidified atmosphere (Thermobrite, Abbott Molecular) at $80^{\circ} \mathrm{C}$ for 8 minutes to denature the probe and target DNA simultaneously, followed by hybridization overnight at $37^{\circ} \mathrm{C}$. The slides were then washed in $2 \times \mathrm{SSC} / 0.3 \% \mathrm{NP}-40$ for 2 minutes at $72^{\circ} \mathrm{C}$. The nuclei were counterstained with 
4,6-diamidino- 2-phenylindole. After hybridization, all slides were maintained at $4{ }^{\circ} \mathrm{C}$ in the dark. FISH signals were assessed using a Zeiss Axioskop microscope.

Scoring was performed by 6 experienced technicians in The Johns Hopkins Cytogenetics Laboratory. These technicians are designated as A to F in the Supplemental Tables 1 to 3, which list raw scoring data for the positive controls, for 40 expected negative controls, and for test cases. Each observer who scored a tumor scored 60 to 100 nuclei. These included nuclei with the following signals: the expected normal 2 fusion signals reflecting intact TFEB alleles; 1 fusion signal; 3 fusion signals; 1 red, 1 green, and 1 fusion signal; 1 red and 1 green signal; 1 green and 1 fusion signal; 1 red and 1 fusion signal; 4 fusion signals; and any other combination rarely observed. The signal pattern of 1 red, 1 green, and 1 intact fusion was the most typical positive pattern for TFEB rearrangement. To avoid false positives due to nuclear truncation, nuclei with only a single color were not included in the scoring. To be scored as a split, the signals had to be separated by a signal diameter $>1$. This was based on the distance between the 2 contigs when the probe was designed and is also considered a standard criterion for most break-apart FISH assays.

To determine a cutoff for a positive result, we examined 12 cases of normal kidney tissue and cases of clear cell RCCs, all of which were negative for rearrangement. The binomial distribution cutoff was calculated using the $\beta$ inverse function from Microsoft Excel with a $95 \%$ confidence level. ${ }^{31}$ Using this method, for a case with 120 scored nuclei to be positive, a cutoff of $>15.8 \%$ of tumor nuclei with split signals was set (see the Results section).

As shown in Supplemental Tables 1 to 3, all positive control cases were scored by 2 to 6 observers, each of whom scored 100 nuclei. Expected negative control cases were scored by 2 observers, each of whom scored 60 to 100 nuclei. Three test cases were scored by 6 observers, each of whom scored 100 nuclei. Four other test cases were scored by 2 observers, each of whom scored 60 nuclei. One test case was scored by only 1 observer, as the slide broke after viewing. This case was included as its result was clear-cut. The number of observers and cells scored is not identical among the tumors partly because of laboratory staffing. More importantly, after our initial experience with the assay, we found that the results were so clear-cut that interobserver variability was not an issue, and fewer observers were thus needed (ie, 2 rather than 6 ). The percentage of nuclei scored as split by each observer was tabulated, and the percentages were averaged among the case observers to give the final mean score for each case.

\section{RESULTS}

The clinicopathologic features of the positive control cases are summarized in Table 1, as well as the mean percentage of split TFEB FISH signals. All 4 genetically confirmed $t(6 ; 11)$ (p21, q12) RCCs demonstrated a high frequency of split TFEB FISH signals (mean of mean scores $=53.2 \%$, range $=31.7 \%$ to $73.5 \%$ ) (Supplemental Table 1, http://links.lww.com/PAS/ A130). One other cytogenetically confirmed case was considered a test failure, as signals could not be detected in the formalin-fixed, paraffin-embedded tissue, likely because of processing artifacts. In contrast, none of the 76 evaluable negative control cases (22 clear cell RCCs, 10 papillary RCCs, 13 chromophobe RCCs, 16 Xp11 translocation RCCs, and 15 
PEComas) demonstrated a high frequency of spilt TFEB FISH signals (mean of mean scores $=1.75 \%$, range $=0 \%$ to $4.2 \%)$ (Supplemental Table 2, http://links.lww.com/PAS/ A131). Five cases, all clear cell RCCs, were test failures as the FISH probe signals could not be detected.

All 9 cases that we suspected to be $\mathrm{t}(6 ; 11)(\mathrm{p} 21 ; \mathrm{q} 12) \mathrm{RCC}$ proved to show TFEB split signals by FISH, thereby confirming the diagnosis genetically (mean of mean scores $=51.4 \%$, range $=35.8 \%$ to $79.2 \%$ ) (Fig. 1) (Supplemental Table 3, http://links.lww.com/PAS/A132). These cases included 1 previously published case, which was resected 46 years before the TFEB FISH assay was applied. ${ }^{16}$ This case had been previously shown to be immunoreactive for TFEB and demonstrated the typical biphasic morphology of the $t(6 ; 11)$ RCCs. The other 8 "test cases" in this study have not been published previously and showed features that expand the clinicopathologic spectrum of these neoplasms (Table 2). For example, test case 2 was extensively hyalinized and ossified and contained only small clusters of epithelioid clear cells without a second population of smaller cells embedded in its thick fibrous wall (Fig. 2). Test case 6 was predominantly oncocytic with a papillary architecture (Fig. 3). Two cases (test cases 4 and 8 ) were extensively cystic, with 1 case (test case 4) having areas that resembled oncocytoma and clear cell RCCs (Fig. 4). Two other neoplasms (test cases 5 and 6) presented with liver metastasis at diagnosis (Fig. 5). One other case (test case 7) arose in a patient with end-stage renal disease. Whereas 6 of these cases demonstrated a second population of smaller cells, in 3 of them the small cell population was only focal. Only 2 cases demonstrated hyalinized basement membrane material, and in none of the cases did the smaller cells cluster around it as is the conventional appearance of $\mathrm{t}(6 ; 11) \mathrm{RCCs}$. We also noted that Melan A labeling was consistently more diffuse than labeling with HMB45, which was completely negative in 4 cases. Moreover, of greater diagnostic importance, only 2 of these 8 test cases (cases 2 and 8) demonstrated convincing nuclear TFEB labeling by IHC. In 3 of the other cases, there was focal labeling of questionable significance at the periphery of the lesion but absence of labeling in the interior, suggesting fixation dependence of TFEB labeling (Fig. 5). One of the other cases was completely negative by TFEB IHC, whereas 2 others were weak and equivocal. Hence, the TFEB FISH assay resolves cases that could not be proven to be $\mathrm{t}(6 ; 11)$ RCC by TFEB IHC.

Parenthetically, all 6 of 6 test cases examined showed nuclear labeling for PAX8, confirming renal origin of the neoplasms and that the tissue fixation permitted nuclear labeling by IHC for some proteins. Sufficient unstained slides from cases 1 and 7 were not available for PAX8 IHC studies.

The clinicopathologic features of the 8 new genetically confirmed cases of $t(6 ; 11)$ RCCs identified in this study, as well as those previously published in the literature, are presented in Table 3. The current study raises the number of genetically confirmed cases from 21 to 30, including the previously published TFEB IHC-positive case mentioned above. 


\section{DISCUSSION}

We report herein the development of a break-apart FISH assay to detect TFEB gene rearrangements that can genetically confirm the diagnosis of $\mathrm{t}(6 ; 11)(\mathrm{p} 21 ; \mathrm{q} 12) \mathrm{RCCs}$ in archival material. On the basis of clinicopathologic, IHC, and molecular similarities to the Xp11 translocation RCCs, $\mathrm{t}(6 ; 11) \mathrm{RCCs}$ have been postulated to be part of a family of translocation RCCs harboring gene rearrangements involving the MiT transcription factor family. However, the clinicopathologic features of $\mathrm{t}(6 ; 11) \mathrm{RCCs}$ have not been well delineated, in large part because only a small number (21) of genetically confirmed cases have been described. This barrier can be overcome if the diagnosis can be confirmed genetically in archival formalin-fixed, paraffin-embedded material. IHC for TFEB is an excellent surrogate for TFEB gene rearrangements; however, it suffers from many of the well-known limitations of IHC, including fixation dependence and lot-to-lot variation of the polyclonal anti-body utilized. Moreover, it is possible that there are other mechanisms of TFEB protein expression that have not been described yet, similar to the recent description of amplification of TFE3 as a mechanism of low-level overexpression of TFE3 protein by IHC. ${ }^{32}$ TFEB FISH overcomes both of these limitations, although it should be noted that FISH was unsuccessful in a small number of cases (approximately 5\%) in this series. Hence, FISH is also fixation dependent (although to a lesser degree than IHC), and we still recommend procurement of fresh tissue for cytogenetics and potential molecular diagnostic assays whenever the diagnosis of translocation RCC is suspected. Nevertheless, the ability to detect a TFEB rearrangement by FISH in a case resected 46 years earlier speaks of the robustness of the TFEB FISH assay.

The differential diagnosis of the $\mathrm{t}(6 ; 11) \mathrm{RCC}$ is broad and includes PEComas, Xp11 translocation RCCs, and conventional clear cell and papillary RCCs. The differential diagnosis with PEComa is particularly difficult, as both $\mathrm{t}(6 ; 11) \mathrm{RCCs}$ and PEComa label for melanocytic markers HMB45 and Melan A but not for S100 protein; in addition, they label for cathepsin $\mathrm{K}$, are typically cytokeratin negative, and feature epithelioid neoplastic cells with clear to eosinophilic cytoplasm. In fact, we know of 2 cases published in the literature in which a t $(6 ; 11) \mathrm{RCC}$ was initially mistaken for a renal PEComa. ${ }^{12,22}$ In addition, Antic et $\mathrm{al}^{33}$ have reported in abstract form that PEComas express TFEB by IHC, although this has not been our experience. TFEB FISH analysis can resolve this differential diagnosis, as we have shown herein that PEComas are negative for TFEB gene rearrangement. In addition, we have found that PEComas almost never label for the renal transcription factor PAX8 (19 of 20 negative, 1 focal positive), whereas this study and our other unpublished results show that the majority of $\mathrm{t}(6 ; 11) \mathrm{RCCs}$ are PAX8 positive, supporting renal tubular differentiation (N. Smith and P. Argani, unpublished data, 2012). t(6;11) RCCs overlap significantly with the Xp11 translocation RCCs, such that we now regard these as 2 members of a larger family of MiT translocation renal carcinomas. Both frequently affect young patients, frequently have epithelioid neoplastic cells with a second population of smaller cells, and are frequently labeled by IHC for melanocytic markers and for cathepsin K. IHC and FISH for TFE3/TFEB can ultimately make this distinction. As our study shows, not all cases of $\mathrm{t}(6 ; 11)$ RCCs contain a characteristic small cell component, and many areas of these neoplasms can be indistinguishable from conventional clear cell RCCs or papillary RCCs. 
FISH and IHC for TFEB can easily resolve these differential diagnoses, but the diagnosis of $\mathrm{t}(6 ; 11)$ RCCs must be suspected before these assays are considered.

In summary, our study adds 8 new cases of $\mathrm{t}(6 ; 11) \mathrm{RCCs}$ to the literature (Table 3$)$. We confirm the malignant potential of these neoplasms, as 2 presented with liver metastasis. We expand the morphologic spectrum to include extensive hyalinization, oncocytoma-like morphology, oncocytic papillary morphology, and absence of a small cell component. Importantly, most of these cases were either negative or equivocal for TFEB by IHC, illustrating the added value of the TFEB FISH assay. The absence of TFEB rearrangements in PEComas supports our view that $\mathrm{t}(6 ; 11) \mathrm{RCCs}$ are distinct from angiomyolipomas/ PEComas and are best classified as RCCs. Utilization of this validated TFEB FISH assay in archival material should permit a more complete delineation of the clinicopathologic spectrum of this distinctive neoplasm.

\section{Supplementary Material}

Refer to Web version on PubMed Central for supplementary material.

\section{References}

1. Argani, P.; Ladanyi, M. Renal carcinomas associated with Xp11.2 translocations/TFE3 gene fusions. In: Eble, JN.; Sauter, G.; Epstein, J.; Sesterhenn, I., editors. Pathology and Genetics of Tumors of the Urinary System \& Male Genital Organs. Lyon, France: IARC; 2004. p. 37-38.

2. Argani P, Antonescu CR, Couturier J, et al. PRCC-TFE3 renal carcinomas: Morphologic, immunohistochemical, ultrastructural, and molecular analysis of an entity associated with the $t(X ; 1)$ (p11.2;q21). Am J Surg Pathol. 2002; 26:1553-1566. [PubMed: 12459622]

3. Argani P, Antonescu CR, Illei PB, et al. Primary renal neoplasms with the ASPL-TFE3 gene fusion of alveolar soft part sarcoma: A distinctive tumor entity previously included among renal cell carcinomas of children and adolescents. Am J Pathol. 2001; 159:179-192. [PubMed: 11438465]

4. Argani P, Hicks J, DeMarzo A, et al. Xp11 translocation renal cell carcinoma (RCC): extended immunohistochemical (IHC) profile emphasizing novel RCC markers. Am J Surg Pathol. 2010; 34:1295-1303. [PubMed: 20679884]

5. Argani P, Laé M, Ballard ET, et al. Translocation carcinomas of the kidney after chemotherapy in childhood. J Clin Oncol. 2006; 24:1529-1534. [PubMed: 16575003]

6. Argani P, Lal P, Hutchinson B, et al. Aberrant nuclear immunoreactivity for TFE3 in neoplasms with TFE3 gene fusions: A sensitive and specific immunohistochemical assay. Am J Surg Pathol. 2003; 27:750-761. [PubMed: 12766578]

7. Argani P, Olgac S, Tickoo SK, et al. Xp11 translocation renal cell carcinoma in adults: expanded clinical, pathologic, and genetic spectrum. Am J Surg Pathol. 2007; 31:1149-1160. [PubMed: 17667536]

8. Komai Y, Fujiwara M, Fujii Y, et al. Adult Xp11 translocation renal cell carcinoma diagnosed by cytogenetics and immunohistochemistry. Clin Cancer Res. 2009; 15:1170-1176. [PubMed: 19228722]

9. Argani P, Lui MY, Couturier J, et al. A novel CLTC-TFE3 gene fusion in pediatric renal adenocarcinoma with $\mathrm{t}(\mathrm{X} ; 17)(\mathrm{p} 11.2 ; \mathrm{q} 23)$. Oncogene. 2003; 22:5374-5378. [PubMed: 12917640]

10. Clark J, Lu YJ, Sidhar SK, et al. Fusion of splicing factor genes PSF and NonO (p54nrb) to the TFE3 gene in papillary renal cell carcinoma. Oncogene. 1997; 15:2233-2239. [PubMed: 9393982]

11. Argani P, Hawkins A, Griffin CA, et al. A distinctive pediatric renal neoplasm characterized by epithelioid morphology, basement membrane production, focal HMB45 immunoreactivity, and $\mathrm{t}(6 ; 11)(\mathrm{p} 21.1 ; \mathrm{q} 12)$ chromosome translocation. Am J Pathol. 2001; 158:2089-2096. [PubMed: $11395386]$ 
12. Argani $P$, Laé M, Hutchinson B, et al. Renal carcinomas with the $\mathrm{t}(6 ; 11)(\mathrm{p} 21 ; \mathrm{q} 12)$. Clinicopathologic features and demonstration of the specific Alpha-TFEB gene fusion by immunohistochemistry, RT-PCR, and DNA-PCR. Am J Surg Pathol. 2005; 29:230-240. [PubMed: 15644781]

13. Davis IJ, Hsi BL, Arroyo JD, et al. Cloning of an Alpha-TFEB fusion in renal tumors harboring the $\mathrm{t}(6 ; 11)(\mathrm{p} 21 ; \mathrm{q} 13)$ chromosome translocation. Proc Natl Acad Sci USA. 2003; 100:6051-6056. [PubMed: 12719541]

14. Kuiper RP, Schepens M, Thijssen J, et al. Upregulation of the transcription factor TFEB in $\mathrm{t}(6 ; 11)$ (p21;q13)-positive renal cell carcinomas due to promoter substitution. Hum Mol Genet. 2003; 12:1661-1669. [PubMed: 12837690]

15. Camparo P, Vasiliu V, Molinie V, et al. Renal translocation carcinomas: clinicopathologic, immunohistochemical, and gene expression profiling analysis of 31 cases with a review of the literature. Am J Surg Pathol. 2008; 32:656-670. [PubMed: 18344867]

16. Geller JI, Argani P, Adeniran A, et al. Translocation renal cell carcinoma: lack of negative impact due to lymph node spread. Cancer. 2008; 112:1607-1616. [PubMed: 18278810]

17. Inamura K, Fujiwara M, Togashi Y, et al. Diverse fusion patterns and heterogeneous clinicopathologic features of renal cell carcinoma with $\mathrm{t}(6 ; 11)$ translocation. Am J Surg Pathol. 2012; 36:35-42. [PubMed: 22173116]

18. Martignoni G, Tardanico R, Pea M, et al. t(6;11) renal cell tumor: a clinicopathological study of two cases in adults. Mod Pathol. 2005; 18:155A. (abstract 715).

19. Pecciarini L, Cangi MG, Lo Cunsolo C, et al. Characterization of $t(6 ; 11)(\mathrm{p} 21 ; \mathrm{q} 12)$ in a renal-cell carcinoma of an adult patient. Genes Chromosomes Cancer. 2007; 46:419-426. [PubMed: 17285572]

20. Petersson F, Vanecek T, Michal M, et al. A distinctive translocation carcinoma of the kidney: "rosette forming," t(6;11), HMB45- positive renal tumor: a histomorphologic, immunohistochemical, ultrastructural, and molecular genetic study of 4 cases. Hum Pathol. 2012; 43:726-736. [PubMed: 22051379]

21. Suarez-Vilela D, Izquierdo-Garcia F, Mendez-Alvarez JR, et al. Renal translocation carcinoma with expression of TFEB: presentation of a case with distinctive histological and immunohistochemical features. Int J Surg Pathol. 2011; 19:506-509. [PubMed: 19687027]

22. Zhan HQ, Wang CF, Zhu XZ, et al. Renal cell carcinoma with $\mathrm{t}(6 ; 11)$ translocation: a patient case with a novel Alpha-TFEB fusion point. J Clin Oncol. 2010; 28:e709-e713. [PubMed: 20823414]

23. Zhong M, De Angelo P, Osbourne L, et al. Translocation renal cell carcinomas in adults: a single institution experience. Am J Surg Path. 2012; 36:654-662. [PubMed: 22446944]

24. Martignoni G, Gobbo S, Camparo P, et al. Differential expression of cathepsin K in neoplasms harboring TFE3 gene fusions. Mod Pathol. 2011; 24:1313-1319. [PubMed: 21602817]

25. Martignoni G, Pea M, Gobbo S, et al. Cathepsin-K immunoreactivity distinguishes MiTF/TFE family renal translocation carcinomas from other renal carcinomas. Mod Pathol. 2009; 22:10161022. [PubMed: 19396149]

26. Argani P, Illei P, Netto G, et al. Distinctive subset of PEComas harbor TFE3 gene fusions. Am J Surg Pathol. 2010; 34:1395-1406. [PubMed: 20871214]

27. Aulmann S, Longerich T, Schirmacher P, et al. Detection of the ASPSCR1-TFE3 gene fusion in paraffin-embedded alveolar soft part sarcomas. Histopathology. 2007; 50:881-886. [PubMed: 17543078]

28. Mosquera JM, Dal Cin P, Mertz KD, et al. Validation of a TFE3 break-apart FISH assay for Xp11.2 translocation renal cell carcinoma. Diagn Mol Pathol. 2011; 20:129-137. [PubMed: 21817901]

29. Zhong M, De Angelo P, Osborne LM, Aisner S, et al. Dual-color, break-apart FISH assay on paraffin-embedded tissues as an adjunct to diagnosis of Xp11 translocation renal cell carcinoma and alveolar soft part sarcoma. Am J Surg Pathol. 2010; 34:757-766. [PubMed: 20421778]

30. Green WM, Netto GJ, Griffin CA, et al. Utilization of a TFE3 break-apart FISH assay in a renal tumor consultation service. Mod Pathol. 2012; 25(S2):210A.

31. Wiktor AE, Van Dyke DL, Stupca PJ, et al. Preclinical validation of fluorescence in situ hybridization assays for clinical practice. Genet Med. 2006; 8:16-23. [PubMed: 16418595] 
32. Macher-Geoppinger S, Roth W, Wagener N, et al. Molecular heterogeneity of TFE3 activation in renal cell carcinomas. Mod Pathol. 2012; 23:308-315.

33. Antic T, Meyer P, Pins M, et al. TFEB immunopositivity in renal angiomyolipomas. Mod Pathol. 2007; 20(S2):135A. (abstract \#608). 

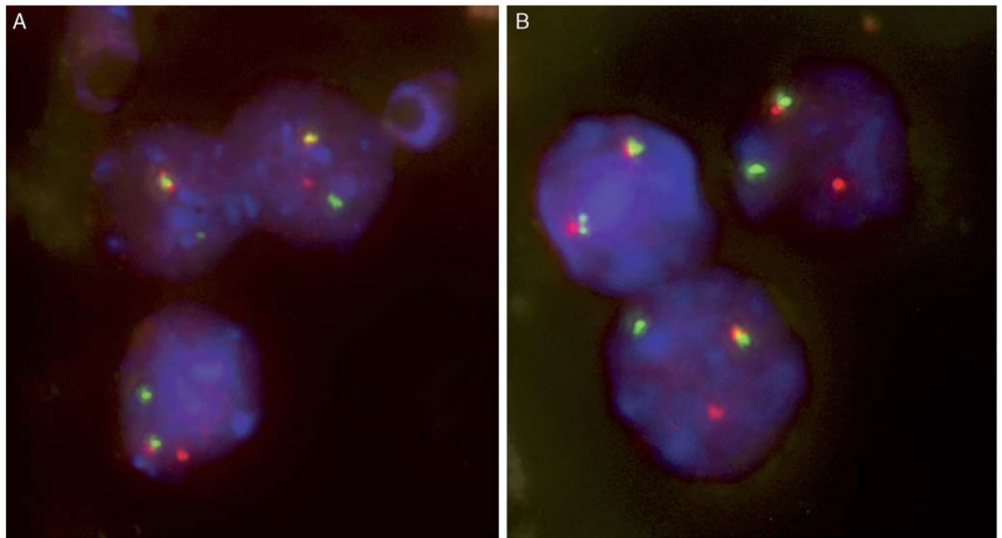

FIGURE 1.

Selected TFEB FISH images from 2 positive test cases. Both of these neoplasms demonstrated split telomeric and centromeric TFEB FISH signals (isolated red and green dots) indicative of a TFEB gene rearrangement, in addition to the expected red-green fusion signal, which indicates an intact TFEB gene. 

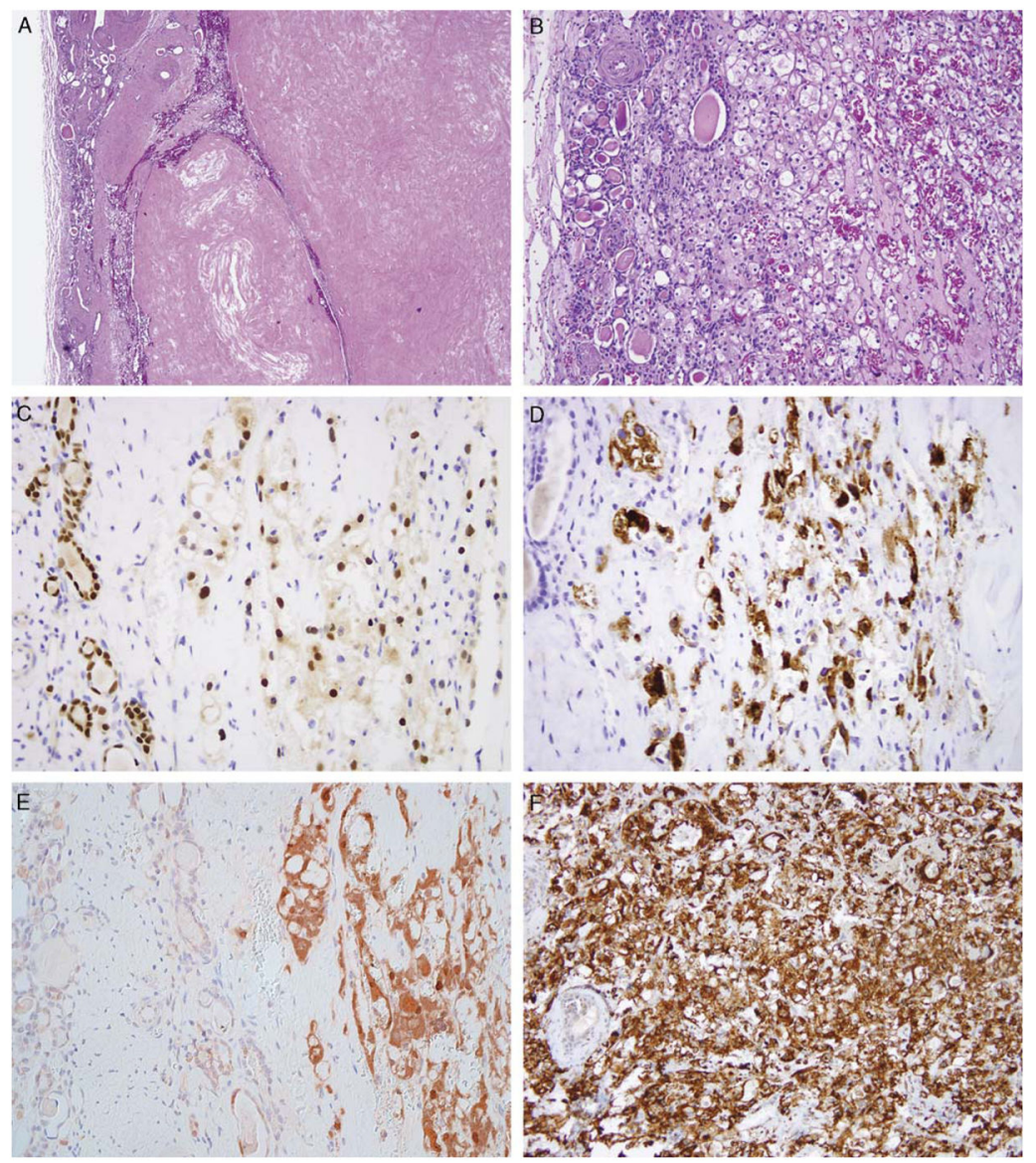

FIGURE 2.

Case 2: this neoplasm was extensively hyalinized (A), with only small clusters of neoplastic epithelium, which mimicked clear cell RCC (B). The neoplasm demonstrated diffuse nuclear labeling for PAX8 (C) and cytoplasmic labeling for Melan A (D). The neoplasm demonstrated nuclear and cytoplasmic labeling for TFEB (E) and was diffuse positive for cathepsin $\mathrm{K}(\mathrm{F})$. This case was proven to harbor a TFEB gene rearrangement by FISH. 

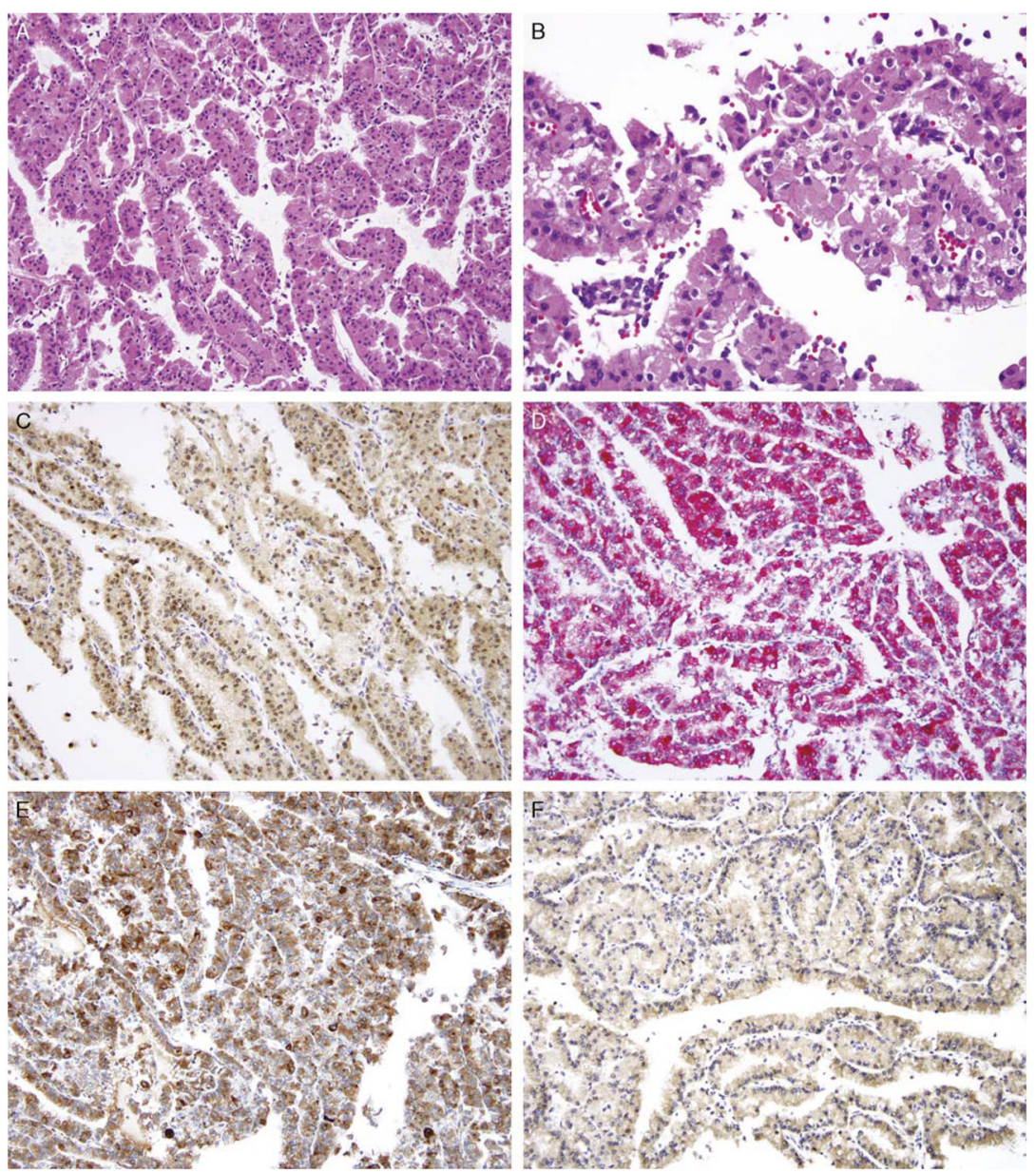

FIGURE 3.

Case 6: this neoplasm demonstrated a predominant papillary oncocytic growth pattern, with only rare clusters of small cells on hematoxylin and eosin stains (A and B). The neoplastic cells demonstrated nuclear labeling for PAX8 (C) and diffuse immunoreactivity for Melan A (D) and patchy immunoreactivity for cathepsin K (E). This neoplasm was almost completely immunonegative for TFEB (F) but was proven by FISH to harbor a TFEB gene rearrangement. 

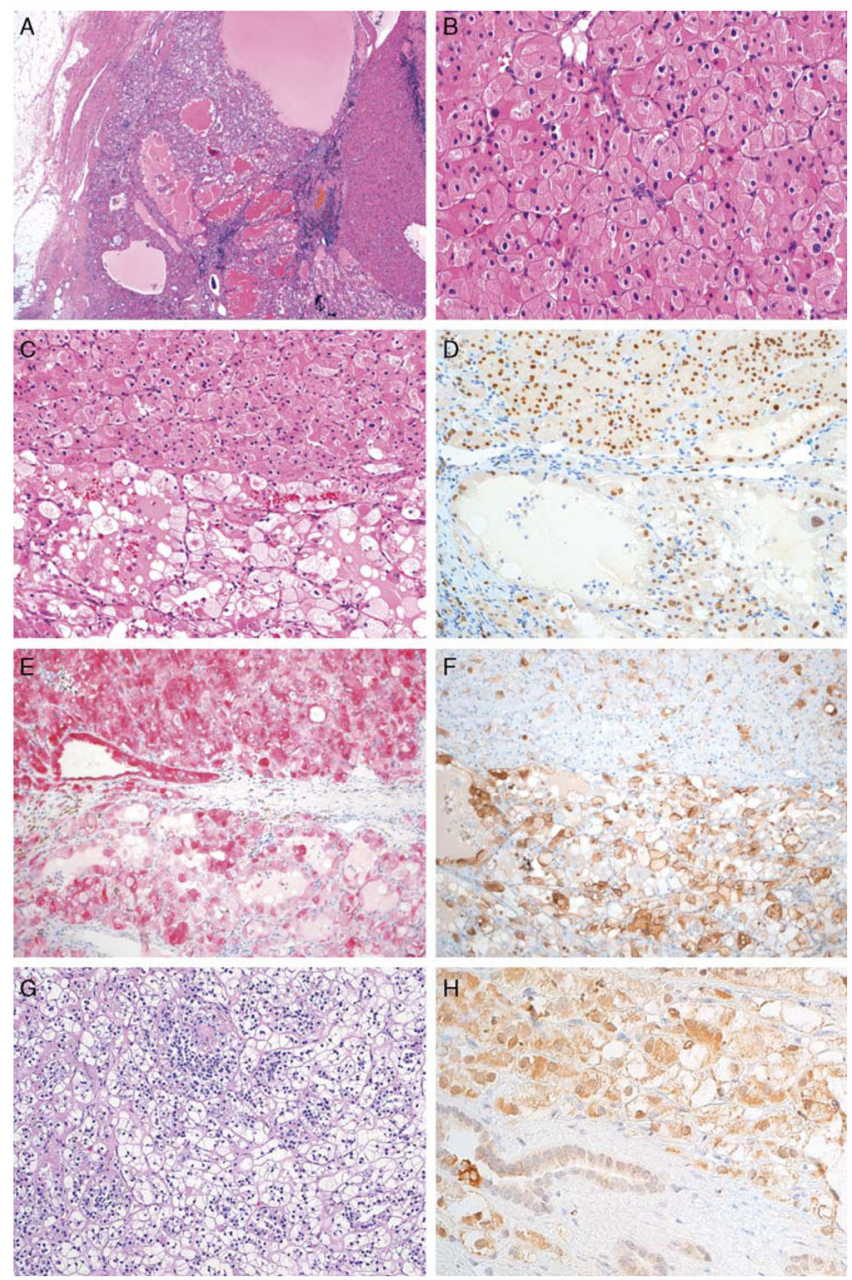

FIGURE 4.

Case 4: this neoplasm demonstrated variable morphology, including areas resembling oncocytoma (A, right; B; C, top) and other areas that resembled clear cell RCC (A, left; C, bottom). Both areas demonstrated diffuse nuclear labeling for PAX8 (D), demonstrated cytoplasmic labeling for Melan A (E), and showed focal labeling for cathepsin K (F). A minority of the neoplasm $(<5 \%)$ demonstrated a more conventional morphology for $\mathrm{t}(6 ; 11)$ RCCs, featuring larger clear cells and smaller cells $(\mathrm{G})$. The neoplasm demonstrated focal moderate immunolabeling for TFEB at its periphery $(\mathrm{H})$, where it intermingled with native renal tubules. This case was proven to harbor a TFEB gene rearrangement by FISH. 

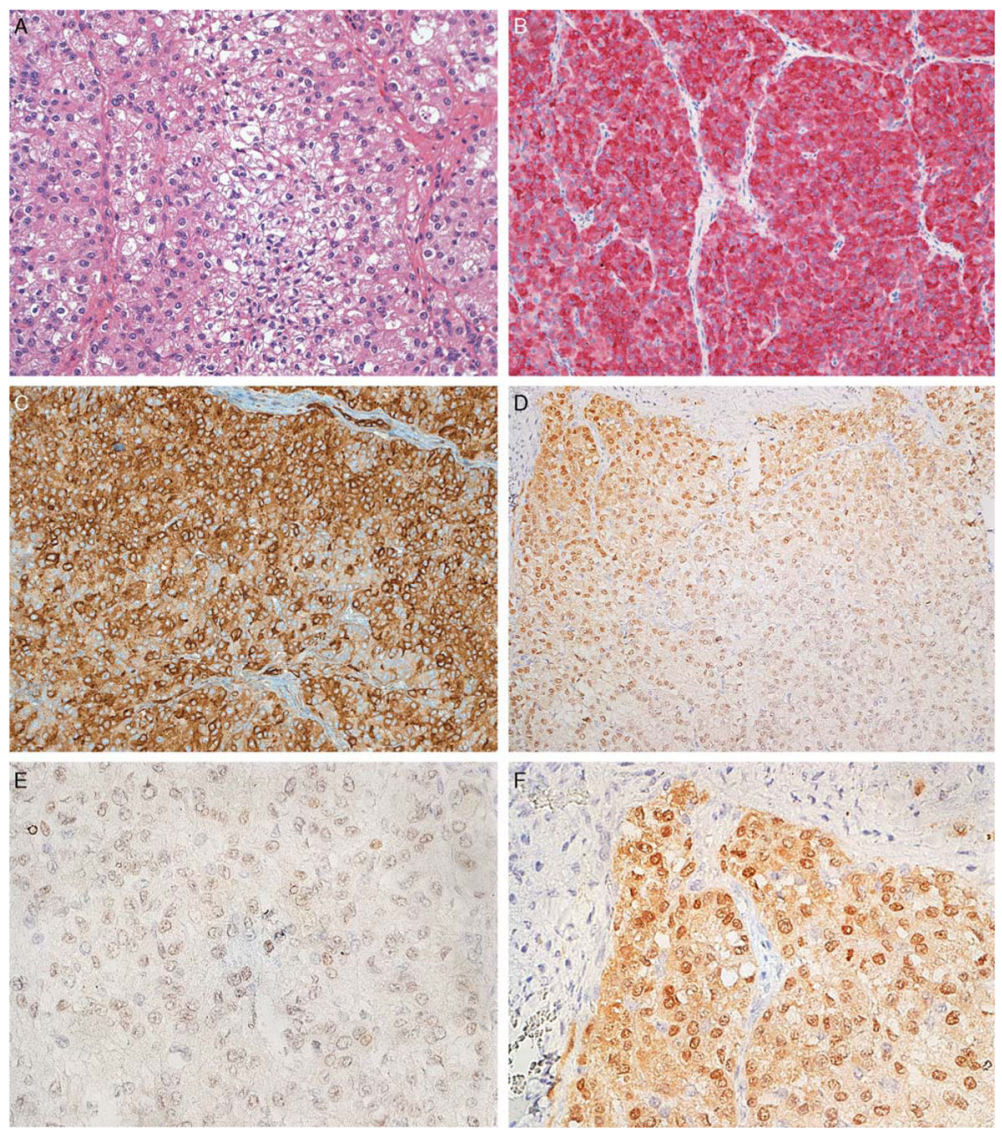

FIGURE 5.

Case 5: this neoplasm demonstrated a solid nested growth pattern, with clusters of somewhat smaller cells located centrally and larger polygonal cells located at the periphery of the nests (A). The neoplasm demonstrated diffuse cytoplasmic labeling for both Melan A (B) and cathepsin K (C) and also labeled for PAX8 (not shown). This neoplasm demonstrated a gradient of TFEB immunoreactivity, which was most prominent at the periphery of the lesion. (D, top of the figure). The central portion of the neoplasm did not show TFEB labeling (E), but the peripheral portion demonstrated moderate nuclear labeling for TFEB (F). This neoplasm demonstrated TFEB gene rearrangement by FISH. 


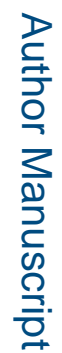

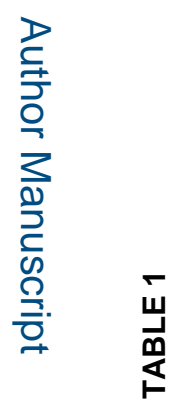

룰

崩

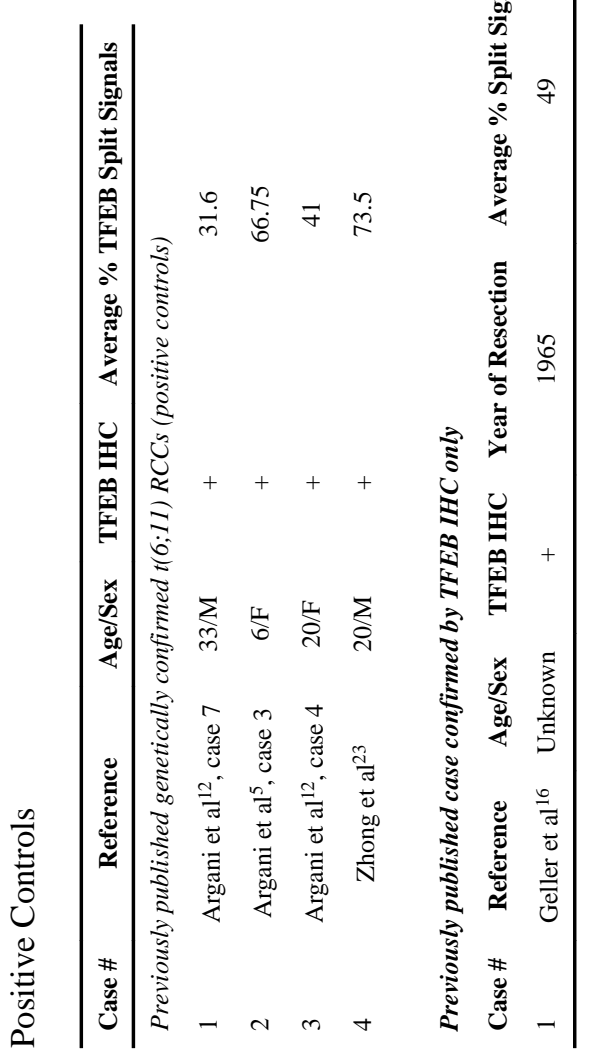

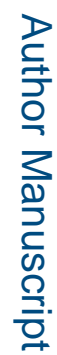

Am J Surg Pathol. Author manuscript; available in PMC 2015 May 22. 


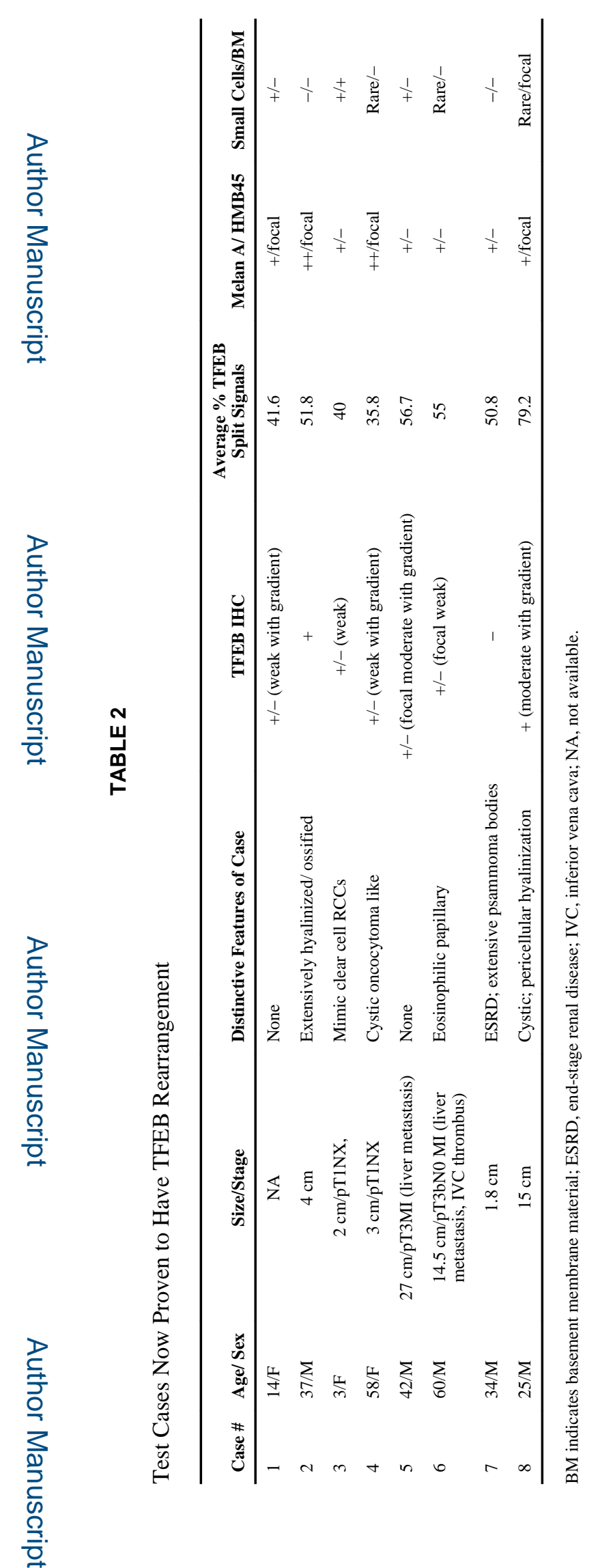

Am J Surg Pathol. Author manuscript; available in PMC 2015 May 22. 

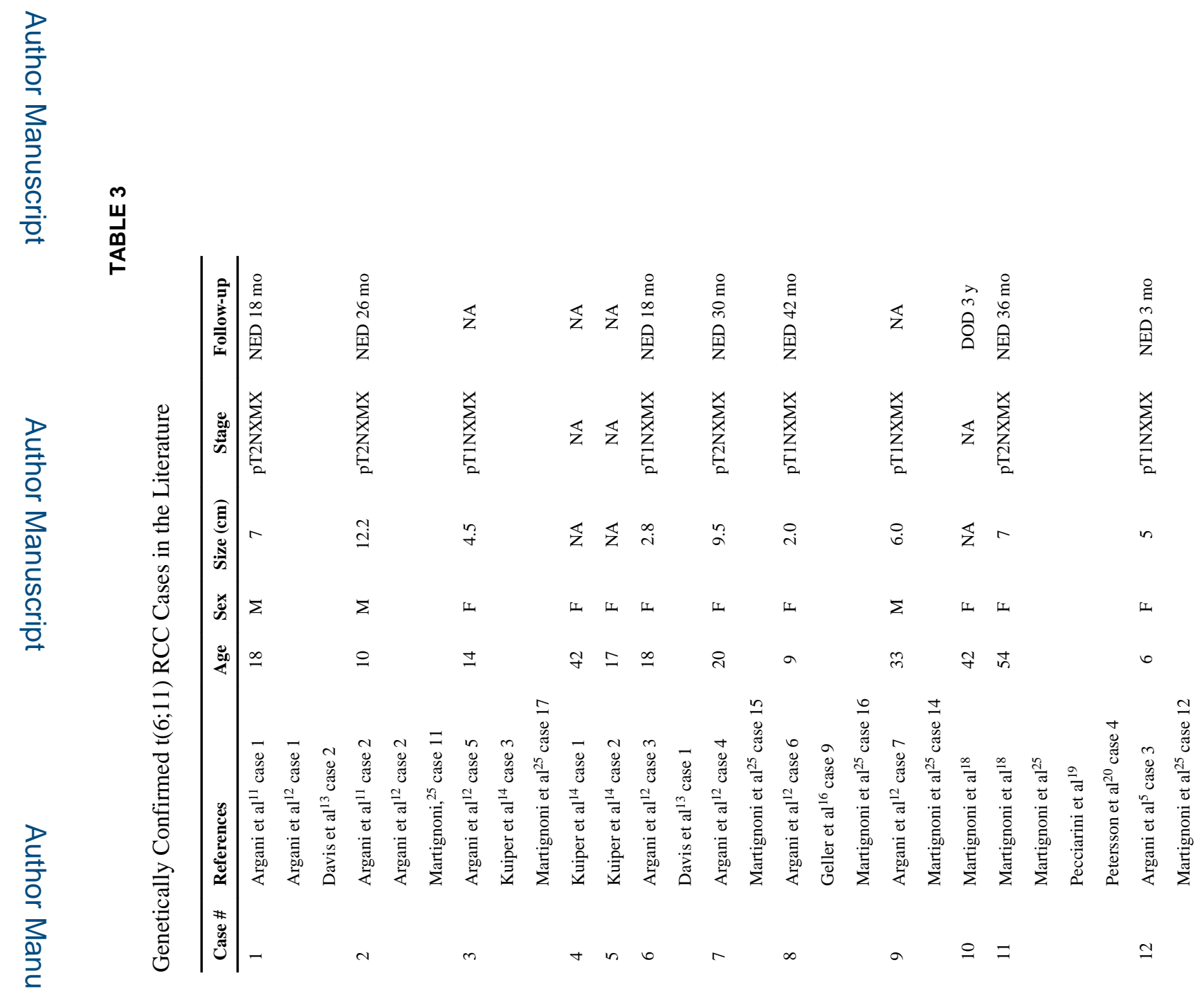

Am J Surg Pathol. Author manuscript; available in PMC 2015 May 22. 
